\title{
MARACATU RURAL NA PROPOSTA PEDAGÓGICA CURRICULAR DA EDUCAÇÃO INFANTIL DE NAZARÉ DA MATA-PE
}

Daiane Lopes da Silva

Adlene Silva Arantes

\section{Resumo}

Investigamos como as políticas curriculares da educação infantil no município de Nazaré da Mata, Pernambuco atendem as orientações das legislações em vigor no âmbito das relações étnico-raciais. $\mathrm{O}$ estudo de cunho qualitativo utilizou a entrevista semiestruturada, a análise documental e o grupo reflexivo. Todas as questões éticas foram atendidas. Percebemos que a história e cultura afro-brasileira e africana ainda são trabalhadas de maneira tímida como afirmaram as participantes da pesquisa, mesmo o maracatu estando presente na proposta curricular para a educação infantil do município. Portanto, faz-se necessário, ações voltadas para a formação continuada dos professores para que possam intensificar práticas que valorizem a cultura afro-brasileira num município em que o maracatu faz parte da vida de muitas famílias e não é abordado como deveria. Uma cultura tão rica que pode contribuir para a formação de sujeitos conscientes de sua identidade cultural, étnica e racial.

Palavras-chave: políticas curriculares; relações étnico-raciais; educação infantil; maracatu rural

\section{RURAL MARACATU IN THE CURRICULAR PEDAGOGICAL PROPOSAL OF CHILDHOOD EDUCATION IN NAZARÉ DA MATA-}

\begin{abstract}
We investigated how the curricular policies of early childhood education in the municipality of Nazare da Mata, Pernambuco meet the guidelines of the legislation in force in the scope of ethnic-racial relations. The qualitative study used the semi-structured interview, the documentary analysis and the reflective group. All ethical issues were answered. We realized that the theme of afro-brazilian and african history and culture is still worked in a timid manner as stated by the research participants, even though maracatu is present in the curriculum proposal for early childhood education in the municipality. Therefore, it is necessary to take actions aimed at the continuing education of teachers so that they can intensify practices that value AfroBrazilian culture in a municipality where maracatu is part of the life of many families and are not addressed as they should be. A culture so rich that it can contribute to the formation of subjects aware of their cultural, ethnic and racial identity.
\end{abstract}

Keywords: curriculum policies; ethnic-racial relations; child education; rural maracatu

\section{MARACATU RURAL EN LA PROPUESTA PEDAGÓGICA CURRICULAR DE EDUCACIÓN INFANTIL EN NAZARÉ DA MATA-}

Resumen

Investigamos cómo políticas curriculares de educación infantil en el municipio de Nazaré da Mata, Pernambuco, cumplen con los lineamientos de la legislación vigente en el ámbito de las relaciones étnicoraciales. El estudio cualitativo utilizó la entrevista semiestructurada, el análisis documental y el grupo reflexivo. Todas las cuestiones éticas fueron respondidas. Notamos que la historia y la cultura temáticas afrobrasileñas y africanas todavía se trabajan de manera tímida, según lo declarado por los participantes de la investigación, a pesar de que maracatu está presente en la propuesta curricular para la educación de la 
primera infancia en el municipio. Por lo tanto, es necesario tomar medidas dirigidas a la educación continua de los maestros para que puedan intensificar las prácticas que valoran la cultura afrobrasileña en un municipio donde el maracatu es parte de la vida de muchas familias y no se aborda como debería ser. Una cultura tan rica que puede contribuir a la formación de sujetos conscientes de su identidad cultural, étnica y racial.

Palabras clave: políticas curriculares; relaciones étnico-raciales; educación infantil; maracatu rural

\section{INTRODUÇÃO}

\section{Ninguém escolheu nascer moreninho cidadão, \\ Se há discriminação, pois não deveria haver. Que o negro sempre épara ter do branco o mesmo valor, \\ O outro ser superior a Naza não descobriu, \\ $E$ até hoje não se viu sendo outra cor. \\ Mestre Anderson Miguel-Maracatu Águia Misteriosa,} 2019)

Este artigo apresenta uma investigação realizada no município de Nazaré da Mata Pernambuco (PE), na qual encontramos a cultura do maracatu rural, também conhecido como maracatu nação ou maracatu de baque solto, presente na proposta curricular para a educação infantil.

Iniciamos o texto com a Loa, cantada pelo atual mestre do Maracatu da Águia Misteriosa, para contextualizar um pouco sobre a nossa investigação. Como é citado pelo mestre Anderson: "Ninguém escolheu nascer moreninho cidadão, se há discriminação, pois não deveria haver..." (2019).

Acreditamos que todos os cidadãos devem aprender a conviver com as diferenças sociais, culturais, étnicas e raciais, religiosas, com atitudes de respeito em todos os contextos. Seguindo o pensamento do mestre, remetemos essa pesquisa aos pequenos cidadãos de Nazaré da Mata, mais precisamente aos que são atendidos na educação infantil do município.

Nosso país é marcado por uma história intensa de desigualdade e discriminação. Entre altos e baixos seguiram as lutas dos grupos sociais, especificamente, o movimento negro em busca de desconstruir as práticas racistas na sociedade brasileira. Há 17 anos fomos contemplados com a Lei n. 10.639/2003, que instituiu a obrigatoriedade dos conteúdos sobre a História e Cultura Afrobrasileira e Africana no currículo da educação brasileira. A lei símbolo de resistência, não se encontra efetivamente cumprida nas instituições escolares, ou seja, na maioria das vezes a questão étnico-racial só é discutida em datas comemorativas. Como é o caso do dia 13 de maio (data da Lei Áurea) que no calendário escolar mais tradicional é o "[...] marco da abolição da escravatura, fato herdado, que traz a ideia de libertação como dádiva e consagra a princesa Isabel como a Redentora dos Escravos" (SILVA, FONSECA, 2010, p. 21).

A Lei n. 10.639/2003 tem o intuito de disseminar caminhos educativos que possam valorizar a cultura afro-brasileira e contribuir para a construção da identidade das crianças negras. Não podemos esquecer que “[...] A Lei n. 10.639/03 teve como função responder às antigas reivindicações do Movimento Negro, mas com novas preocupações - principalmente com a implantação da mesma” (DIAS, 2003, p. 59). Nesse sentido, concordamos com Cunha Jr. (2003, p. 269) quando afirmou que:

A proposta da lei de inclusão é ampla e necessária nos seus diversos aspectos. Ampla, pois liga dois espaços geográficos continentais, África e Brasil, através de um período histórico e cultural longo, de pelo menos cinco mil anos. Tem como principal tarefa fazer a ponte de conhecimentos entre os elementos da História e 
da Cultura dos afrodescendentes no âmbito local, em cada bairro, em cada município, com os dos estados e regiões, até o âmbito nacional, e destes a um contínuo do passado africano. São elementos da história da humanidade no sentido mais amplo, e têm como principal efeito cumprir o direito que a Constituição nos dá de obter o conhecimento da nossa história e da nossa cultura.

Nessa direção, investigamos como as políticas curriculares da educação infantil no município de Nazaré da Mata atendem as orientações das Diretrizes Curriculares Nacionais para a Educação das Relações Étnico-Raciais e para o Ensino de História e Cultura Afro-brasileira e Africana. Este questionamento nos despertou para as problemáticas que orientaram a nossa investigação: 1) Até que ponto a proposta pedagógica curricular para a educação infantil, contempla as orientações da referida lei e das Diretrizes Curriculares Nacionais para a Educação das Relações Étnico-Raciais?; 2) Em que medida a Secretaria de Educação tem investido na formação continuada dos sujeitos / profissionais envolvidos na educação infantil através de políticas educacionais?

Essa investigação foi realizada no município de Nazaré da Mata, localizado na Zona da Mata do estado de Pernambuco, situado a $68 \mathrm{~km}$ de distância do Recife, capital do estado. O município tem uma área de $150,3 \mathrm{~km}^{2}$, e uma população média de 32.471 habitantes segundo as estimativas levantadas pelo IBGE (2019).

Nazaré da Mata é mais conhecida como a Capital Estadual do Maracatu. Apresenta uma cultura acompanhada de sentimentos e simplicidade, que conquistam a todos com seu brilho natural. A cultura do maracatu rural, também chamado de Maracatu de Baque Solto é passada de pai para filho e resistindo assim ao tempo. O maracatu rural não só encanta, como também transmite a história da região. Não se trata apenas de uma dança, ou, até mesmo, de uma brincadeira carnavalesca, é a cultura de um povo.

O termo "baque" é sinônimo de toque e "baque solto" é o ritmo com a presença de instrumentos de percussão (caixa, surdo, gongé, cuíca e poíca) e de sopro em sua orquestra. "O próprio ritmo, o baque solto é mais agressivo e remete a luta e opressão, evidenciam a dança do caboclo, a forma que ele se apresenta, com rapidez, caindo ao chão, simulando uma briga, toque frenético, representando seu momento de libertação" (MEDEIROS, 2003, p. 210).

O maracatu é uma cultura de resistência. Seus componentes brincam, dançam e expressam suas angústias e desejos, nos versos declamados em suas apresentações, também conhecidos como as Loas do maracatu. Entre um verso e outro, apresentam questões que buscam melhorias para seu povo. Reverenciam os companheiros que já partiram, como também pessoas especiais que se fortificam com a cultura do maracatu rural. Suas vestimentas encantadoras dão brilho ao cortejo. Cores fortes e brilhosas de suas golas transmitem nos cortejos a sensação de leveza, que representam os movimentos que as folhas da cana-de-açúcar fazem ao vento.

\section{PERCURSO METODOLÓGICO}

Essa investigação foi conduzida no âmbito da pesquisa qualitativa. Segundo os estudos de Godoy, a pesquisa qualitativa apresenta características importantes que ajudam o pesquisador entender melhor suas particularidades.

O estudo empírico é realizado no seu ambiente natural, pois os fatos sociais têm que ser observados e analisados inseridos no contexto ao qual pertencem, através de contato direto, desempenhando o pesquisador um papel fundamental na observação, seleção, consolidação e análise dos dados gerados; como os diferentes tipos de dados existentes na realidade são considerados importantes para a compreensão do fenômeno social em estudo (GODOY, 1995, p. 62). 
Baseando-nos nesse tipo de abordagem, realizamos a entrevista semiestruturada, direcionada à diretora de ensino do município, para conhecer como se conduz o ensino e trabalho da gestão na educação infantil referente à questão étnico-racial.

Posteriormente, analisamos documentos que fundamentam a educação infantil do município. Primeiro nos debruçamos sobre a Base Nacional Comum Curricular (BNCC) adentrando na parte referente à modalidade da educação infantil, intercalando com as questões debatidas na entrevista semiestruturada, seguindo com a análise da Proposta Pedagógica Curricular da Educação Infantil do município.

Na sequência, realizamos o Grupo Reflexivo (GR). O Grupo Reflexivo é uma técnica de coleta de dados: nele podemos encontrar características do grupo focal, como também do grupo discussão. Nessa perspectiva, estima-se que o GR contribui para uma "[...] reflexão com o grupo sobre a experiência vivida que permite experienciar questões de ordem afetiva, cognitiva, sociocultural, que vão além daquelas de caráter puramente teórico e metodológico, discutidas na disciplina" (PASSEGGI, 2011, p. 150).

Participaram da pesquisa: a diretora de ensino do município; a coordenadora da educação infantil; quatro supervisoras pedagógicas responsáveis pela educação infantil. Todas receberam nome de cores simbolizando as vestimentas coloridas dos grupos brincantes do Maracatu. Nomeamos aleatoriamente a diretora de ensino de Laranja; a coordenadora de Branco; e as supervisoras de Azul, Lilás, Vermelho e Amarelo para preservar a identidade das participantes.

Todas as participantes são profissionais efetivas do município, e entre elas há profissionais graduadas em Pedagogia e Geografia. Nosso Grupo Reflexivo foi dividido em três partes: passado, presente e futuro, nas quais buscamos compreender os caminhos percorridos no sistema educacional pelas participantes, deixando em evidência a questão étnico-racial, uma vez que o Grupo Reflexivo nos proporcionou um espaço de diálogo em que as participantes se sentiram confiantes e estimuladas a falar de suas vivências enquanto estudantes e profissionais, pois a escuta sensivel reconhece a aceitação incondicional do outro. Nesse processo, a escuta sensível é um método que afirma " $[. .$.$] grande possibilidade de crescimento, pois à medida que se escuta as angústias do outro,$ há uma aproximação deste, um conhecimento, e, ao conhecermos o outro, aprendemos a nos conhecer também" (BARBIER apud CERQUEIRA, 2011, p. 16).

Configura-se como uma possibilidade de interação entre os sujeitos, que pode aprimorar as relações humanas e as ações formativas de tal modo "[...] que o sujeito se constitui como alguém que, ao mesmo tempo em que se apropria da fala e da cultura, se constrói como pessoa e reconstrói a realidade em que vive, numa constante interação com os outros" (BARBIER apud CERQUEIRA, 2011, p. 12).

A educação infantil é ofertada na rede pública do município de Nazaré da Mata em seis instituições localizadas na zona urbana e quatro instituições na zona rural, que desenvolvem atividades escolares no turno da manhã, bem como no turno da tarde. As creches atendem crianças de 0 a 3 anos e as escolas de educação infantil atendem crianças de 4 e 5 anos.

O percurso da análise dos dados adotado para essa investigação tomou como referência os estudos de Bogo (2010), que discute a questão da identidade; e Laraia (1986) que dialoga sobre cultura. Vale ressaltar que a pesquisa atendeu todas as questões éticas ao ser submetida ao comitê de ética, CEP-CONEP Parecer n. 3.255.571. A seguir, apresentaremos os dados coletados nesse percurso.

\section{AS TECITURAS DE SABERES QUE SE ENTRELAÇAM FORTIFICANDO A CULTURA E A EDUCAÇÃO}


Nos últimos anos, inquietações predominaram no cenário da educação básica brasileira. Em busca de soluções, foi pensado um novo documento regente para a educação brasileira: a proposta curricular denominada Base Nacional Comum Curricular (BNCC), que tomou forma a cada encontro, e se intensificou diante do foco da igualdade de conteúdo para todas as regiões brasileiras. Nesse sentido, Melo e Sudbrack (2018) afirmam que:

A formulação e aprovação da BNCC geraram muitas discussões, debates e críticas. Há aprovações e desaprovações em relação à proposta da mesma, assim como, um grande desafio e expectativas para que seja colocada em prática, atendendo as necessidades da educação brasileira (MELO; SUDBRACK, 2018, p. 11).

A primeira versão da BNCC foi apresentada para consulta pública pelo Ministério da Educação (MEC) no ano de 2015. Após as primeiras reuniões de debates, ocorreram questionamentos, porque a sociedade civil se sentiu ausente durante a construção do documento. A BNCC levantou entre pesquisadores e educadores inúmeros questionamentos, e ainda gera polêmicas mesmo depois de concluído seu processo de elaboração.

Com todas as implicações levantadas inicialmente, a primeira versão necessitou passar por releituras e debates com a finalidade de melhorar os pontos negativos e incluir outros conteúdos. Após tentar realizar os reajustes expostos à primeira versão da Base, houve a inclusão de professores, como também de alguns profissionais da gestão escolar nas reuniões realizadas nos estados. Intensificava-se, assim, seu foco para a padronização do ensino. A discussão continuou com a pretensão de criar uma conexão dos diversos saberes e conteúdos na educação brasileira.

A versão final da Base Nacional Comum Curricular foi promulgada pelo Ministro da Educação José Mendonça Bezerra Filho no ano de 2017. Segundo Melo e Sudbrack (2018, p. 13) apresentou o questionamento realizado pela professora Maria do Carmo Martins,

Que explicou que a elaboração da BNCC como política de Estado é um projeto legítimo e estava prevista na LDB promulgada em 1996. Considera, porém, que no atual momento histórico não é conveniente a existência da BNCC, pois as discussões sobre esta ocorreram num momento de profundo conflito social e que as divergências acirradas entre os diferentes grupos que participaram do processo refletiram no documento.

Entre os questionamos, pergunta-se como é possível padronizar a educação em um país que apresenta muitas diferenças em seus contextos social, cultural, econômico, entre outros? Equalizar a educação brasileira se torna duvidoso e contraditório diante dos questionamentos sociais.

A BNCC, com o princípio de padronização, “[...] não alude à diversidade de infâncias e ao ensino especial, ao tratar das experiências e objetivos de aprendizagem" (BARBOSA, 2018, p. 4). Em seu contexto, mostra a necessidade da aplicação de testes avaliativos entre as crianças na educação infantil, expressando um retrocesso político. Da maneira como está proposta, "[...] a BNCC serve de modo equivocado à proposição de um processo avaliativo e formativo homogeneizador tanto das crianças quanto de seus professores" (BARBOSA, 2018, p. 5).

É importante destacar que o uso do termo diversidade na BNCC é problemático, porque acaba sendo muito abrangente, ao propor dar conta de vários sujeitos historicamente excluídos do sistema educacional brasileiro: os adultos, os indígenas, os quilombolas, como pode ser observado a seguir:

Essas decisões precisam, igualmente, ser consideradas na organização de currículos e propostas adequados às diferentes modalidades de ensino (Educação 
Especial, Educação de Jovens e Adultos, Educação do Campo, Educação Escolar Indígena, Educação Escolar Quilombola, Educação a Distância), atendendo-se às orientações das Diretrizes Curriculares Nacionais. é imprescindível que os alunos identifiquem a presença e a sociodiversidade de culturas indígenas, afro-brasileiras, quilombolas, ciganas e dos demais povos e comunidades tradicionais para compreender suas características socioculturais e suas territorialidades (BNCC, 2018, p. 366).

Consta na BNCC (2018), a unidade temática O sujeito e seu lugar no mundo em que se focalizam as noções de pertencimento e identidade. Em relação à educação infantil, essa unidade deve ser trabalhada,

Por meio do aprofundamento de seu conhecimento, sobre si mesmas, e de sua comunidade, valorizando-se os contextos mais próximos da vida cotidiana. Espera-se que as crianças percebam e compreendam a dinâmica de suas relações sociais e étnico-raciais, identificando-se com a sua comunidade e respeitando os diferentes contextos socioculturais (BNCC, 2018, p. 360).

Mas como fazer isso? Essa competência dirige-se aos conteúdos destinados à convivência entre os indivíduos. Consta no documento:

[...] na Educação Infantil, as crianças ampliem os seus conhecimentos e apreço pelo seu corpo, identifiquem os cuidados necessários para a manutenção da saúde e integridade do organismo e desenvolvam atitudes de respeito e acolhimento pelas diferenças individuais, tanto no que diz respeito à diversidade étnico-cultural quanto em relação à inclusão de alunos da educação especial (BNCC, 2018, p. 325).

Portanto, a BNCC não apresenta questões específicas relacionadas à história e cultura afrobrasileira. Em seu contexto, traz uma ideia generalizada da temática étnico-racial, principalmente na educação infantil. Priorizando o lúdico, nessa etapa a BNCC deixa lacunas relacionadas à construção da identidade étnico-racial das crianças. Um exemplo das lacunas é a colocação do termo diversidade no corpo textual, posta de maneira generalizada. Portanto, a maneira incoerente do uso da palavra "[...] serve para não deixar definido o que exatamente pretende-se contemplar. Diversidade por si só não pode ser entendido como um conceito que contempla todos os grupos da diversidade étnica" (CARTH, 2017, p. 7).

Trazemos, então, as questões discutidas na entrevista semiestruturada realizada com a diretora de ensino. Assim direcionamos nosso primeiro questionamento: qual seria a opinião da participante diante da Base Nacional Comum Curricular e quais melhorias poderiam ocorrer na educação infantil? A participante aponta, no seu discurso, a BNCC como um documento que veio,

Padronizar a educação, afirma que existem críticas em relação à base, porém, pensa que ela também apresenta mais pontos positivos do que negativos; vê que a BNCC vai nivelar o ensino, uma vez que, antes, cada profissional interpretava de uma maneira os documentos regentes da educação, alguns trabalhavam intensificando o brincar, outros só a escrita ou mesmo a matemática e, no final de sua fala, intensifica que a base padroniza o ensino (Participante Laranja, 2019).

Sua resposta aponta questões que precisam ser refletidas, pois a imagem de padronização da educação brasileira nos inquieta bastante. Como podemos impor uma padronização da educação como algo positivo, em uma sociedade que apresenta um alto índice de desigualdade social? A imagem de padronização apresentada pela BNCC distorceu-se perante a realidade brasileira.

Seguindo, perguntamos à participante: no corpo do texto, a BNCC apresenta cinco campos de experiências a serem desenvolvidos pelos sujeitos. Em sua opinião, como a temática das relações 
étnico-raciais aparece nesses campos de experiências? A participante, no que lhe concerne, afirma que "[...] A base deixa a ideia muito livre, generaliza a temática. Já o currículo da educação infantil de Pernambuco deixa mais 'amarrada' a questão racial do que em relação à BNCC" (Participante Laranja, 2019).

No momento, refletimos com a participante sobre os campos de experiência presentes na BNCC em relação à questão étnico-racial: no primeiro campo, nomeado como $o$ eu, o outro e o nós, esclarece-se que é direito das crianças ter "[...] oportunidade de ampliar o modo de perceber a si mesmas e ao outro, valorizando sua identidade, respeitando os outros e reconhecendo as diferenças que nos constituem como seres humanos" (BRASIL, 2016, p. 37).

No campo corpo, gestos e movimentos, a criança é reconhecida como sujeito que, desde cedo, "[...] explora o mundo, os objetos e o espaço a sua volta, estabelecendo relações, expressam-se, brincam e produzem conhecimentos sobre si, sobre o outro, sobre o universo social e cultural" (BRASIL, 2016, p. 37).

Seguindo, o campo intitulado traços, sons, cores e formas apresenta que a criança deve "[...] conviver com diferentes manifestações artísticas, culturais e científicas, locais e universais no cotidiano escolar, possibilitando, assim, a vivência de experiências diversificadas" (BRASIL, 2016, p. 37).

Por último, encontramos espaços, tempos, quantidades, relações e transformações quando a criança deverá ter oportunidades para ampliar seus conhecimentos do mundo físico e sociocultural. " $\mathrm{O}$ mundo sociocultural compreende as relações de parentesco e sociais entre as pessoas que conhece; como vivem e em que trabalham essas pessoas; quais suas tradições e costumes; a diversidade entre elas etc." (BRASIL, 2016, p. 38).

Ao analisarmos esse pequeno recorte realizado nos campos das experiências a serem desenvolvidas na educação infantil, percebemos que a questão cultural se apresenta nos quatros campos, de forma ampliada. Frequentemente, ouvimos e vemos nos meios de comunicação notícias sobre o racismo e, para mudar essa situação, precisamos persistir em práticas antirracistas. Nessa perspectiva, sondamos a participante, em relação a sua posição de ex-coordenadora da educação infantil e atual diretora de ensino: "você já presenciou alguma escola se interessando em trabalhar a questão étnico-racial durante o ano letivo sem ser durante as datas comemorativas"? Ela afirmou que:

Já aconteceu de algumas escolas se interessarem em trabalhar a questão do bullying, pois estava acontecendo alguns casos de preconceito na sala de aula. Então, para combater esta questão, criaram um projeto que trabalhou a imagem do eu e do outro. Foram utilizados até espelhos para as crianças se verem... (Participante Laranja, 2019).

Segundo Candau (2011, p. 246):

As diferenças são então concebidas como realidades sócio-históricas em processo contínuo de construção-desconstrução-construção, dinâmicas, que se configuram nas relações sociais e estão atravessadas por questões de poder. São constitutivas dos indivíduos e dos grupos sociais. Devem ser reconhecidas e valorizadas positivamente no que têm de marcas sempre dinâmicas de identidade, ao mesmo tempo em que combatidas as tendências a transformá-las em desigualdades, assim como a tornar os sujeitos a elas referidos objetos de preconceito e discriminação.

Para finalização de nossa entrevista semiestruturada atuante como instrumento de sondagem, perguntamos se a Secretaria de Educação proporciona formação continuada para 
discutir / trabalhar a temática das Relações Étnico-Raciais? E se, em algum momento, perceberam alguma resistência por parte dos gestores, supervisores e professores em relação à proposta de trabalhar a história e cultura afro-brasileira e africana no cotidiano escolar da educação infantil. A participante pontificou que não. "[...] Não se empolgam com a temática, só quando é algo pontual, pois não é algo de se trabalhar constantemente, só em caso de necessidade" (Participante Laranja, 2019).

Percebemos que o ensino da História e Cultura afro-brasileira e africana nas instituições de educação infantil do município ainda se restringe a datas comemorativas e pudemos detectar na entrevista que ainda existem práticas racistas nas escolas. Quantas crianças precisam passar por esse processo doloroso chamado preconceito racial para que os profissionais envolvidos na educação comecem a trabalhar a temática de maneira eficaz? Seria mais pertinente a prática diária, uma construção que evitaria muitas situações que marcam as crianças negativamente por toda a sua vida, pois quando nos conhecemos enquanto sujeitos sociais e somos valorizados fortalecemos a nossa autoestima.

Voltando à BNCC, entre os direitos de aprendizagem e de desenvolvimento na educação infantil, apresenta-se o conviver, o brincar, o participar, o explorar, o expressar e o conbecer-se. Gostaríamos de destacar o conhecer-se, por meio do qual podemos identificar a importância e direito de "[...] construir nas crianças a sua identidade pessoal, cultural e social, construindo uma imagem positiva de si e de seus grupos de pertencimento, envolvendo-se nas diversas experiências vivenciadas na instituição escolar" (BRASIL, 2016, p. 35).

Nessa etapa inicial da vida social, as crianças buscam referências, primeiramente, em seu núcleo familiar. Posteriormente, em pessoas que participam ativamente de sua rotina, e a escola, sendo sua segunda casa, pode influenciá-las positiva ou negativamente. Logo, após a entrevista, pudemos afirmar que o trabalho com a questão étnica e racial ainda se resume a contornar atitudes discriminatórias, uma vez que suas ações são pontuais - em datas específicas, ou no caso de constrangimentos vivenciados no âmbito escolar.

\section{A PROPOSTA PEDAGÓGICA CURRICULAR DA EDUCAÇÃO INFANTIL}

Apresentaremos a análise da Proposta Pedagógica Curricular da Educação Infantil (PPCEI) de Nazaré da Mata e, assim, buscamos observar se segue as orientações das Diretrizes Curriculares Nacionais para a Educação das Relações Étnico-Raciais para o Ensino de História e Cultura Afrobrasileira e Africana, como também a presença da cultura local em seu contexto construtivo.

$\mathrm{Na}$ PPCEI encontramos um tópico voltado para a cultura e o maracatu rural, discorrendo um pouco da história do maracatu rural em Nazaré da Mata, o número de grupos brincantes, como também a importância da inserção do maracatu rural no currículo da educação infantil do município. Entretanto, ao observarmos os eixos apresentados pela PPCEI, o maracatu rural não aparece com tanta evidência como transcrito no início do tópico.

Uma cidade cultural e histórica na qual encontramos uma cultura singular, não poderia deixá-la passar despercebida no contexto escolar, pois "[...] a cultura é a marca do homem, sendo aquilo que ele cria, produz, realiza. A cultura é a alma de um ciclo, é a produção de um povo" (SANTOS, 1963 apud PEREIRA, 2012, p. 40). Nas reivindicações trazidas pelo Movimento Negro no século XX destaca-se a necessidade de diretrizes que orientem a formulação de "[...] projetos e propostas pedagógicas empenhadas na valorização da história e cultura dos afro-brasileiros e dos africanos, assim como projetos e propostas pedagógicas comprometidos com a educação das relações étnico-raciais positivas" (BRASIL, 2005, p. 9). 
Como mencionamos, a manifestação cultural mais evidente em Nazaré da Mata é o maracatu rural. Essa manifestação se originou com o intuito de a população afro-brasileira vivenciar e relembrar de maneira camuflada a cultura de coroação dos reis do Congo. Em terras pernambucanas, o maracatu foi recebendo influências dos povos indígenas, tornando-se, então, uma manifestação cultural espetacular e única. Reconhecido como patrimônio cultural, Pernambuco instituiu o dia $1^{\circ}$ de agosto como Dia Estadual do Maracatu Rural, com a Lei n. 11.506 em 22 de dezembro de 1997. Em 2001, pela Lei n. 174/2011, Nazaré da Mata foi nomeada como Capital do Maracatu.

A palavra maracatu se origina do instrumento conhecido como maracá, utilizado pelos indígenas em momentos festivos. Trata-se do chocalho. "[...] Associamos o termo ao MARACA com a sílaba TU, toque, batida forte, de modo que o termo Maracatu se configura como batido de maracá, palavra de origem tupi guarani, configurando assim o termo que temos hoje, Maracatu" (FRANÇA, 2019, p. 39). São vários os personagens presentes no maracatu rural:

Caboclo de lança é a figura central do Maracatu, protetor da brincadeira ele destacase com seu chapéu brilhante, feito com chapéu de palha, uma armação de ferro, coberto por papel madeira em formato arredondado e ornado de fitas multicoloridas cintilantes, exibindo seu brilho esplêndido ao vento. No rosto, um cravo na boca.

O Arreiamá caboclo sem lança também chamado de caboclo de pena. Em sua mão, leva um machado e, em sua cabeça, um chapéu ornado com penas. A atividade desse caboclo é proteger o casal real, a dama do paço e as baianas, tido como defensor da natureza, vem para defender sua tribo. Sua performance é exuberante, dança rápida, agachando-se, sempre com seu machado à mão, decorado com fitas. Com seu penacho feito de penas de pavão, pesado, posto em sua cabeça, embeleza o cortejo.

A Dama do paço é a baiana central, incumbida de levar a boneca, chamada de calunga. É esta boneca que guarda todo o feitiço do Maracatu. Ela é tida como símbolo de proteção. Protege a nação dos males. As Baianas são mulheres centrais do Maracatu, utilizam saias rodadas, bordadas, coloridas e armadas com arames. Antes, as baianas eram homens vestidos de mulher, pois, como já mencionado, não tinha participação da mulher na brincadeira.

Catita, Mateu e a burra são os três personagens centrais no Maracatu. São personagens que ficam à frente, abrindo caminho para o cortejo passar. A catita é a figura engraçada, com a cara pintada, é um homem vestido de mulher, que faz sua performance ao lado de seu esposo, o Mateu, um personagem também com a cara pintada, chapéu de funil e roupa de chita. A burra com seu chicote abre espaço, anuncia a chegada da nação. Todos estes circulam por fora do Maracatu (FRANÇA, 2019, p. 40-44).

Existe ainda o Terno, o conjunto musical responsável pelo batuque, “[...] o som frenético, rápido que do ritmo leva os folgazões à loucura. O som é constituído pelo caixa ou tarol, surdo, gonguê e a cuíca ou porca, bem como de instrumentos de sopro que auxiliam o cortejo" (FRANÇA, 2019, p. 44). Por fim:

Mestre e Mestras de Maracatu são os responsáveis pela produção das Loas, os versos improvisados no momento das apresentações. $\mathrm{O}(\mathrm{a})$ mestre(a) de Maracatu, vestido sempre com chapéu de palha e camisas coloridas, caminha com sua bengala, enfeitada por fita ou com anéis metálicos, símbolo de sua autoridade no brinquedo. Com seu apito sempre à mão e posto na boca, direciona todo o movimento da caboclaria. $\mathrm{O}(\mathrm{a})$ mestre(a) fica à frente da bandeira e próximo ao 
terno. Ao seu lado, tem o(a) contramestre, seu auxiliar, que repete com o grupo de baianas os últimos versos cantados por ele(a). Ao apito do (a) mestre (a), o terno para toda a nação silencia para ouvir a sua Loa, os caboclos de lanças se ajoelham, mostrando reverência ao canto do(a) mestre(a). Vale ressaltar que no Maracatu também temos a presença do bandeirista, que leva a bandeira com o nome, ano e fundação do Maracatu, para que todos conheçam a quem se refere. $\mathrm{E}$ dos sombreiros, que levam o guarda-sol, protegendo a corte real (FRANÇA, 2019, p. 44).

Os principais grupos de maracatu atuantes na cidade de Nazaré da Mata são: Cambinda Brasileira, Cambindinha de Araçoiaba, Coração Nazareno, Leão Formoso, Leão Misterioso, Águia Misteriosa, Leão de Olho, Sonho de Criança, Estrela Brilhante, Águia de Ouro, Leão Africano, Leão Faceiro, Águia Dourada, Estrela da Tarde, Cambinda Nova, Cambinda de Ouro e Leão Tucano (FRANÇA, 2019, p. 45).

Fortalecendo-se com as histórias e tradições, o maracatu necessita da reverência dos jovens e da dedicação dos mais velhos para que ele possa continuar resistindo diante desses sujeitos históricos que foram massacrados, que souberam resistir e continuam hoje afirmando "[...] suas identidades fortemente na nossa sociedade, mas numa situação de relações de poder assimétricas, de subordinação e acentuada exclusão" (CANDAU, 2011, p. 126). Uma cultura passada de pai para filho, de avó para neto perpassou o tempo, mostrando sua resistência e seus encantos, entre os cortejos acompanhados com os fortes passos, com os sambas, as repercussões e as marchas. Misterioso, contendo traços de identidade afro-brasileira e indígena. Cultural e artístico, o maracatu tende a resgatar e (re)construir o processo identitário de cada cidadão.

Adentrando a PPCEI identificamos que:

A Proposta Pedagógica Curricular da Educação Infantil de Nazaré da Mata foi reformulada no ano de 2015, seguindo as orientações da Lei de Diretrizes e Base da Educação Nacional (LDB), das Diretrizes Curriculares Nacionais para a Educação Infantil (DCNEI) e do Referencial Curricular Nacional para a Educação Infantil (RCNEI), baseada nos princípios éticos da autonomia, da responsabilidade, da solidariedade e do respeito ao bem comum, ao meio ambiente e às diferenças culturais, identidades e singularidades. Seguindo com os princípios políticos: dos direitos de cidadania, do exercício da criatividade e do respeito à ordem democrática. E por fim, o estético: da sensibilidade, da criatividade, da ludicidade e da liberdade de expressão nas diferentes manifestações artísticas e culturais (SECRETARIA MUNICIPAL DE EDUCAÇÃO, 2015, p. 4).

Ao analisarmos o corpo do texto da PPCEI, encontramos vestígios da cultura local do município. Há um tópico sobre a Educaşão Infantil e Cultura - O Maracatu Rural. O referido tópico sinaliza a cultura do maracatu em Nazaré e descreve um pouco sobre ele. Segundo o documento, em Nazaré da Mata existem aproximadamente 20 grupos de maracatu rural, considerados mais tradicionais, tendo como destaque o maracatu feminino Coração Nazareno, fundado em 2004. Em meio às descrições realizadas nesse tópico, encontramos a informação da existência do grupo do maracatu mirim chamado Sonho de Criança. Ele surgiu em "[...]1997 de uma iniciativa da Secretaria de Turismo e Cultura e em uma concepção futurista de garantir às próximas gerações a beleza da festa. O referido maracatu é composto em média por 70 crianças entre 10 a 14 anos" (SECRETARIA MUNICIPAL DE EDUCAÇÃO, 2015, p. 29). A seguir trazemos uma imagem que retrata a apresentação do Maracatu Mirim Sonho de Criança:

Figura 1: Maracatu Mirim Sonho de Criança 


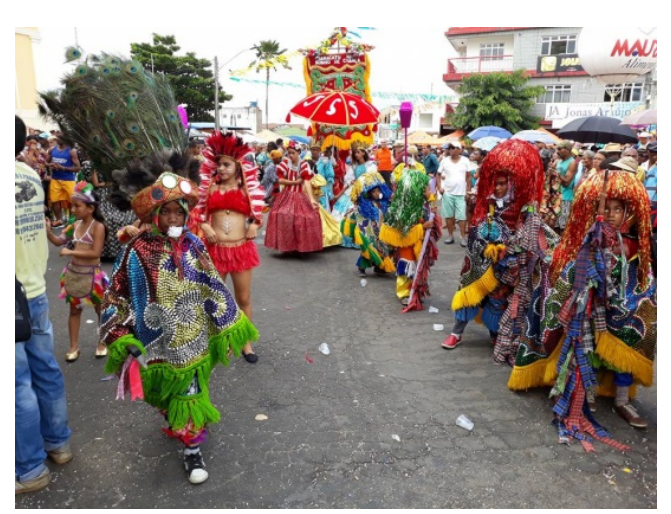

Fonte: https://www.facebook.com/prefeituradenazaredamata/posts/376535169423204, 2018.

Continuando com a investigação, encontramos o seguinte parágrafo que descreve a importância da inserção do maracatu rural no currículo da educação infantil:

\begin{abstract}
A inserção do maracatu rural no currículo da Educação Infantil visa à valorização da cultura local, vivências dessa cultura nas instituições de Educação Infantil, uma vez que é um espaço educativo e, portanto, propício a oportunizar experiências, envolvendo a cultura. Ressalta-se, portanto, a espontaneidade e a naturalidade como as crianças manifestam no dia a dia através das brincadeiras e cantorias, experiências adquiridas no ambiente familiar e em seu entorno, cabendo à escola, sistematizar esses conhecimentos de forma lúdica e significativa (SECRETARIA MUNICIPAL DE EDUCAÇÃO, 2015, p. 29).
\end{abstract}

Entretanto, quando chegamos aos eixos trabalhados na PPCEI o maracatu rural não apareceu como evidenciado no tópico citado anteriormente. Os eixos são direcionados para as crianças de 2 a 3 anos e de 4 a 5 anos.

No eixo: identidade e autonomia, encontramos competências e conteúdos que trabalham a questão da identidade do sujeito entre crianças de 4 e 5 anos.

No eixo: movimento, música, artes visuais, linguagem oral e escrita, matemática, não encontramos nenhuma competência ou conteúdo que discuta a questão cultural, ou a história afro-brasileira e africana.

O único eixo no qual encontramos algo sobre a cultura local do município foi o eixo: natureza e sociedade. Os conteúdos e habilidades relacionadas ao maracatu rural, para as crianças de 2 e 3 anos, foram valorização do maracatu rural como patrimônio cultural local; participar das festividades envolvendo o maracatu rural e datas comemorativas. Para as crianças de 4 e 5 anos, apresentam como os conteúdos e habilidades maracatu rural: patrimônio cultural local; reconhecer o maracatu rural como patrimônio cultural local; participar das festividades envolvendo o maracatu rural.

Diante do exposto, podemos afirmar que a PPCEI não está seguindo as orientações das Diretrizes Curriculares Nacionais para a Educação das Relações Étnico-Raciais. Essas Diretrizes afirmam que o reconhecimento requer a adoção de políticas educacionais e de estratégias pedagógicas de valorização da diversidade, de modo a superar a desigualdade étnico-racial presente na educação escolar brasileira. Nesse sentido, não podemos esquecer que "[...] o currículo é, definitivamente, um espaço de poder. O conhecimento corporificado no currículo carrega as marcas indeléveis das relações sociais de poder, ou seja, o currículo reproduzindo culturalmente as estruturas sociais (SILVA, 2005, p. 147).

Por fim, realizamos o Grupo Reflexivo (GR), formulado para atender nossas inquietações perante a gestão escolar responsável pela educação infantil. O GR foi composto por três 
momentos, cada um direcionado para um tempo escolar vivenciado pelos sujeitos, criando situações que possibilitaram o desvendamento das memórias escolares e profissionais. No terceiro momento do Grupo Reflexivo as participantes foram questionadas enquanto gestão: o podemos fazer para que a temática das Relações Étnico-Raciais esteja presente no cotidiano escolar da educação infantil? Naquele momento, o silêncio se cruzou com os olhares pensativos, e todas fizeram a mesma afirmação: "nossas escolas já trabalham a questão racial durante todo o ano letivo". Como agentes mediadores no processo reflexivo do GR tornamos a perguntar: de qual forma é trabalhada a questão racial durante o ano letivo e a questão cultural presente no município?

Todas as participantes afirmaram que "são trabalhadas nas datas comemorativas". Exemplificaram que a questão do maracatu rural é bastante trabalhada no período carnavalesco, no qual são levados os representantes dos grupos do maracatu rural para as escolas para eles falarem da história local e da tradição rural do município.

Essa abordagem da cultura local é indispensável para as crianças nazarenas, pois atua como reforço da construção identitária cultural. É válido relembrar que Nazaré da Mata, entre as demais cidades localizadas na Zona da Mata Norte de Pernambuco, é caracterizada por guardar "[...] grandes histórias e ricas memórias das tradições que perpassam o tempo. Dentre suas manifestações culturais, Nazaré da Mata destaca-se com as poesias de cordel, o maracatu, a ciranda, os caboclinhos, os artesanatos" (CABRAL, 2014, p. 13).

Essas heranças culturais atuam como possibilidades de trabalhar a cultura local durante todo ano letivo, buscando arcabouço no método da interdisciplinaridade. De acordo com Haas (2003, p. 122), “[...] vivenciar a interdisciplinaridade exige do educador a superação da prática individual, sem abandoná-la, assumindo-a com todas as suas contradições, pois se parte do individual para se buscar o coletivo". E é no coletivo que construímos grandes possibilidades com finalidades do êxito.

Em relação à temática étnico-racial, as supervisoras afirmaram que os educadores trabalham no período do folclore, "quando destacamos o personagem do saci que é negro, também é discutida no dia 20 de novembro". Esse tipo de prática pode interferir na construção da identidade da criança. Nesse contexto, Bernardes et al. (2012, p. 66) afirmam que:

Temos que entender que a formação de sua identidade pode ser afetada, pois, esses lugares de socialização, de trocas de saberes, aprendizagem, ao trabalhar a imagem do negro brasileiro estereotipada, pode acarretar a negação de suas identidades, contribuindo para um perigoso processo de negação de si mesmo.

Daí a necessidade de compreender que a escola tem um papel importante na construção das identidades que devem começar já na educação infantil.

Nesta instância, cabe ressaltar que há crianças que sofrem ainda com este não reconhecimento ou com um reconhecimento precarizado e, além disso, com o não pertencimento a diversos lugares na sociedade, principalmente na escola. Isso impacta em sua autoestima, tornando-se uma criança frágil, enfraquecendo seu rendimento escolar ou sua ida à instituição, dentre outras sequelas emocionais (SILVA, SILVA, 2015, p. 34).

Em uma só voz, as participantes relataram que o trabalho feito só não está presente de maneira oficial na PPCEI do município. Portanto, não basta estar posto no currículo para que se efetive. Nesse contexto, Cardoso (2005, p. 9) expressa que:

É fundamental, também, que a elaboração dos currículos e materiais de ensino tenha em conta a diversidade de culturas e de memórias coletivas dos vários grupos étnicos que integram nossa sociedade. É obrigação do Estado a proteção 
das manifestações culturais das culturas populares, indígenas e afro-brasileiras, bem como dos demais grupos participantes de nosso processo civilizatório. Essa obrigação deve refletir-se também na educação.

O processo do pensar, do (re)construir de forma coletiva, em que todos possam contribuir com suas experiências adquiridas nas jornadas diárias na educação, fortifica o currículo. Nesse caso, a PPCEI necessitará direcionar novos olhares para as questões culturais e pertencimento étnicoracial dos sujeitos. As participantes exemplificaram que a questão do maracatu rural é bastante trabalhada no período carnavalesco, quando são levados os representantes dos grupos de maracatu rural para as escolas para falarem da história local e da tradição rural do município.

Perante as colocações feitas no terceiro momento do GR pelas participantes em relação aos novos caminhos a serem pensados, percebemos que a sociedade brasileira ainda se encontra com travas, quando se trata de dialogar sobre a questão étnico-racial. E para que essas interferências sejam quebradas, necessitamos de um trabalho contínuo, através de momentos em que as vivências dos profissionais fortaleçam novas medidas, tendo como objetivo a discussão da temática desde a educação infantil.

Finalizando a coleta de dados propusemos, para o município, sugestões para o processo de reestruturação da PPCEI. Nessa perspectiva, buscamos contribuir com sugestões de conteúdos que valorizem a cultura e história afro-brasileira e africana como, também, a valorização da cultura local do município, agregando algumas contribuições ao processo formador da identidade cultural e social das crianças de Nazaré da Mata.

Apresentaremos, assim, nas formações continuadas oferecidas pelo município, a partir de uma parceria com a Universidade, possibilidades de como desenvolver práticas pedagógicas que valorizem as relações étnico-raciais, pois “[...] o professor ocupa um papel importante na aprendizagem dos estudantes. Como agente de transformação social, ele levará ao estudante o ensino e mostrará os caminhos a serem explorados no decorrer da sua vida" (SILVA, ARANTES, 2018, p. 106).

As sugestões para o processo de reestruturação da PPCEI seguiram orientações da Base Nacional Comum Curricular, do Currículo de Pernambuco para a Educação Infantil, das Diretrizes Curriculares Nacionais para a Educação Infantil e as orientações presentes nas Diretrizes Curriculares para Educação das Relações Étnico-Raciais e o Ensino da História e Cultura Afrobrasileira e Africana, que reafirmam a Lei n. 10.639/2003. Entendemos que a temática deve ser inserida no contexto escolar durante todo o ano letivo de maneira interdisciplinar, não de maneira dissociativa, como pensaram muitos profissionais da educação quando foi sancionada a Lei $\mathrm{n}$. $10.639 / 2003$. 


\section{CONSIDERAÇÕES FINAIS}

A investigação nos possibilitou perceber que a PPCEI não segue as orientações das Diretrizes Curriculares Nacionais para a Educação das Relações Étnico-Raciais e para o Ensino de História e Cultura Afro-Brasileira e Africana.

Como forma de contribuir para o processo formador comprometido com as singularidades das crianças de Nazaré da Mata construímos, a partir dos depoimentos das participantes, sugestões de conteúdos que pudessem ser incluídos durante a reestruturação da PPCEI. Procuramos valorizar a cultura e história afro-brasileira e africana como, também, a cultura do maracatu rural, da ciranda e do coco de roda.

Entre as contribuições, sugerimos que fossem inclusos para crianças de 1 ano e 7 meses a 3 anos e 11 meses, no campo de experiência (corpo, gestos e movimentos) apresentado pela BNCC, a apreciação musical da ciranda e do coco de roda. No campo de experiência (o eu, o outro e o nós), a construção do conceito de identidade (eu) em relação à sua origem e cultura. Por fim, no campo de experiência (traços, sons, cores e formas), respeitar e valorizar as próprias produções, a dos colegas e dos vários artistas locais apresentados em sala e/ou no convívio social em que a criança se encontra.

Para crianças de 4 e 5 anos e 11 meses, propusemos que fosse inserido no campo de experiência (corpo, gestos e movimentos), a apreciação dos estilos musicais: ciranda, samba, loas de maracatu, coco de roda. No campo de experiência (o eu, o outro e o nós), entrar em contato com o mundo letrado e familiarizar-se com a leitura e escrita, voltando-se para a história e cultura afro-brasileira, por meio de contos africanos e da literatura afro-brasileira. Por fim, no campo de experiência (traços, sons, cores e formas), trabalhar com obras artísticas produzidas na localidade, fortificando o respeito e o valor da cultura local.

Concluindo o processo da escrita desse artigo, retornamos à questão inicial, que se originou a partir da necessidade de investigar como as políticas curriculares da educação infantil do município estavam atendendo às orientações das Diretrizes Curriculares Nacionais para a Educação das Relações Étnico-Raciais e para o Ensino de História e Cultura Afro-brasileira e Africana. Ao analisar a PPCEI identificamos que a cultura afro-brasileira está representada pelo maracatu rural, mas só é discutida em datas comemorativas, como o carnaval.

Portanto, a presença do maracatu rural na PPCEI serviu como suporte para intensificarmos a história e cultura afro-brasileira nos sujeitos, e contribuir na reestruturação da PPCEI. Esse percurso nos auxiliou na elaboração da inserção social da investigação, por meio de um Seminário Formador direcionado aos profissionais atuantes na educação infantil, previsto para acontecer no ano de 2020, em parceria com a Universidade de Pernambuco, que buscará garantir um momento de interação e trocas de saberes sobre práticas pedagógicas antirracistas.

\section{REFERÊNCIAS}

BARBOSA, Ivone Garcia. A BNCC e a regulação da educação infantil: perspectivas críticas. CONAPE - Conferência Nacional Popular da Educação. Brasília/DF, 2018.

BERNARDES, Aparecida Martins. Educação para as relações étnico-raciais: outras perspectivas para o Brasil. Uberlândia, Minas Gerais: Ed. Gráfica Lopes, 2012.

BRASIL. IBGE. Censo demográfico: Nazaré da Mata - PE. Disponível em https://cidades.ibge.gov.br/brasil/pe/nazare-da-mata/panorama. Acesso em 20 maio 2020. 
BRASIL. Ministério da Educação. Base Nacional Comum Curricular. Proposta preliminar. Segunda versão revista. Brasília: MEC, 2016.

BRASIL. Ministério da Educação. Diretrizes Curriculares Nacionais para a Educação das Relações ÉtnicoRaciais e para o Ensino de História e Cultura Afro-brasileira e Africana. Brasília: MEC, 2005.

BRASIL. Secretaria Especial de Políticas de Promoção da Igualdade Racial. Plano Nacional de Implementação das Diretrižes Curriculares Nacionais para as Relações Étnico-Raciais e para o Ensino de História e Cultura Afro-Brasileira e Africana. Brasília, jun. 2009.

BOGO, Ademar. Identidade e luta de classes. 2. ed. São Paulo: Expressão Popular, 2010.

CANDAU, Vera Maria Ferrão. Diferenças culturais, cotidiano escolar e práticas pedagógicas. Curriculo sem Fronteiras, v. 11, n. 2, p. 240-255, jul./dez. 2011.

CARDOSO, Fernando Henrique. Prefácio à $2^{a}$ impressão. MUNANGA, Kabengele (ed./org.). Superando o racismo na escola. 2. ed. rev. Brasília: Ministério da Educação, Secretaria de Educação Continuada, Alfabetização e Diversidade, 2005.

CABRAL, Geovani Gomes. Poesia na Mata Norte de Pernambuco: história e versos de uma região. Revista Canavial. Associação Reviva, v. 4. Ano 1 - jan.-fev. 2014.

CARTH, John Land. A base nacional comum curricular e a aplicação da política de educação para educação das relações étnico-raciais (afro-brasileira, quilombola, cigana). Disponível em http://etnicoracial.mec.gov.br/26-publicacoes/214-artigos. Acesso em 29 abr. 2020.

CERQUEIRA, Teresa Cristina Siqueira (con.). Textos em escuta sensivel. Brasília, Thesaurus, 2011.

CUNHA Jr. Henrique. Nós, afro-descendentes: história africana e afro-descendente na cultura brasileira. ROMÃO, Jeruse (org.). História da Educação do Negro e outras histórias. Secretaria de Educação Continuada, Alfabetização e Diversidade. Brasília: Ministério da Educação, Secretaria de Educação Continuada, Alfabetização e Diversidade, 2005.

DIAS, Lucimar Rosa. Quantos passos já foram dados? A questão de raça nas leis educacionais. Da LDB de 1961 à Lei 10.639 de 2003. ROMÃO, Jeruse (org.). História da educação do negro e outras bistórias. Secretaria de Educação Continuada, Alfabetização e Diversidade. Brasília: Ministério da Educação, Secretaria de Educação Continuada, Alfabetização e Diversidade, 2005.

FRANÇA, Ana Cláudia de. "Loas de Maracatu de Baque Solto" no contexto da Educação de Jovens e Adultos: estratégias para alfabetizar com gênero da tradição oral. Universidade de Pernambuco. Programa de Pós-graduação em Educação. Mestrado Profissional. Dissertação de Mestrado, Nazaré da Mata, 2019.

GODOY, Arilda Schmidt. Pesquisa Qualitativa - tipos fundamentais. Revista de Administraşão de Empresas. São Paulo: RAE, v. 35, p. 20-29, maio/jun. 1995.

HAJE, Lara. Fórum Nacional de Educação considera Base Nacional Curricular Comum ilegitima. Câmara dos Deputados: $\quad$ Brasília, $2017 . \quad$ Disponível http://www2.camara.leg.br/camaranoticias/noticias/educacao-e-cultura/535651-forumnacional-de-educacao-considera-base-nacional-curricular-comum-ilegitima.html. Acesso em 2 jun. 2019.

LARAIA, Roque de Barros. Cultura: um conceito antropológico. Rio de Janeiro: Zahar, 1986.

MEDEIROS, Roseana Borges de. Maracatu rural: luta de classes ou espetáculos? (Um estudo das expressões de resistência, luta e passivização das classes subalternas). Tese (Doutorado em Serviço Social). Programa de Pós-Graduação em Serviço Social da Universidade Federal de Pernambuco, Recife, 332f., 2003. 
MELO, Ana Paula Barbieri de; SUDBRACK, Edite Maria. Caminhos da educação infantil: da Constituição de 1988 até a BNCC. Revista Internacional de Educação Superior. Campinas, São Paulo. v. 5, 2019.

PEREIRA, Meira Chaves. Cultura, infância, criança e cultura infantil: alguns conceitos. Quaestio, Sorocaba, São Paulo, v. 15, n. 1, p. 38-49, maio 2012.

PASSEGGI, Maria da Conceição. A experiência em formação. Rev. Educação, Porto Alegre, v. 34, n. 2, p. 147-156, maio/ago. 2011.

SECRETARIA MUNICIPAL DE EDUCAÇÃO. Proposta Pedagógica Curricular da Educação Infantil. Nazaré da Mata, 2015.

SILVA, Daiane Lopes da; ARANTES, Adlene Silva. Uma prática pedagógica norteada por narrativas e contos afro-brasileiros e africanos. In: Literatura Afro-brasileira e Africana: experiências formadoras na extensão, no ensino e na pesquisa. 1. ed. Recife, PE: EDUPE, 2018, v. único, p. 103-116.

SILVA, Kennya; SILVA, Luciana F. As questões raciais na educação infantil: possibilidades e desafios em uma dimensão pedagógica. Revista Simbiótica. v. 2, n. 1, jun. 2015.

SILVA, Marcos Antônio da; FONSECA, Selva Guimarães. Ensino de História hoje: errâncias, conquistas e perdas. Rev. Bras. Hist. [online]. 2010, v. 30, n. 60, p. 13-33.

Submetido em março de 2020

Aprovado em agosto de 2020

\section{Informações sobre as autoras}

Daiane Lopes da Silva

Mestra em Educação (PPGE) pela Universidade de Pernambuco Campus Mata Norte (2017 - 2019), na linha de Política e Gestão Educacional. Assistente de Recursos Humanos pelo o Instituto Tecnológico Brasileiro (2018).

E-mail: dainlopes@gmail.com

ORCID: https://orcid.org/0000-0002-1082-3460

Link Lattes: http://lattes.cnpq.br/5889621598433632

Adlene Silva Arantes

Docente da Universidade Federal de Pernambuco - Campus Mata Norte. Líder do Grupo de Estudos Étnico-racial e ambiental (GERA).

E-mail: adlene.arantes@gmail.com

ORCID: https://orcid.org/0000-0002-7007-0237

Link Lattes: http://lattes.cnpq.br/0093014121449327 